\title{
Angiogenic Switches Play a Critical Progression in Cancer
}

\author{
Nozlena A Samad ${ }^{a}$, Ahmad Bustamam Abdul ${ }^{b}$, Rasedee Abdullah ${ }^{b}$, Heshu Rahman ${ }^{b, d}$, KZ Khor $^{a}$, Max Stanley \\ Chartrand ${ }^{c}$
}

\begin{abstract}
Tumor angiogenesis has become an important field of research over the past decade due to its crucial role in the growth and spread of cancer. Significant amount of literature has demonstrated the link between tumor angiogenesis, metastasis, and prognosis. Not all tumors are angiogenesis-derived and the angiogenesis switch is a sign of the ability of tumor and inflammatory cells to produce angiogenesis factors in tumor microenvironment. Endothelial cell genetic stability plays an important role in this phenomenon as it makes it less likely to build up resistance towards agents aimed at tumor vasculature. Furthermore, since a minor $0.05 \%$ of the adult human body undergoes angiogenesis at any given moment, the potential side effects of anti-angiogenesis treatments is minimal. This study focuses on the role of and methods of modulating angiogenesis in tumor development.
\end{abstract}

Keywords: Angiogenesis; Metastasis; Tumors

Abbreviations: VEGF, vascular endothelial growth factor

\section{Introduction}

Cancer is a very complicated disease characterised by uncontrolled, unregulated cell growth. Cancer happens when abnormal cells grow to such an extent that they synthesize their own blood vessels (angiogenesis) and break free from the tumor and start spreading to other body systems. This process, called metastasis,

Significance | Understanding angiogenesis and its mechanical process is crucial for the development of new treatment.

${ }^{*}$ Correspondence: Integrative Medicine Cluster, Advanced Medical and Dental Institute, Universiti Sains Malaysia, 13200 Kepala Batas, Penang, Malaysia. E-mail: nozlena@usm.my, Tel: (0) +604 - 562 2051, (hp) +6012 - 4118772, Fax: $+604-5622349$.

Edited by Md Asaduzzaman Shishir, University of Dhaka, Bangladesh, and Md Shamsuddin Sultan Khan, Hawkesbury Institute for the Environment, University of Western Sydney, Hawkesbury Campus, Bourke Street, Richmond, NSW AUSTRALIA 2753 and accepted by the Editorial Board May 4, 2018 (received for review April 5, 2018) is what characterizes cancer. There are many other mechanistic process that develops caner including inflammatory cytokines, and anti-apoptotic cancer biomarkers. The ultimate goal of all micro-mechanism is further supported when cancer builds new blood vessels for itself. The cancer sends cancer cells out through the lymphatic system or through the blood stream and the newly established micro-metastasis goes through the process of angiogenesis. Cancer cells get nutrients through the blood vessels and it can grow and grow until it sends further cancer cells through the body to spread the cancer further. Each time this angiogenesis smartly involved to harmonize the entire cancer cell metabolic systems. Thus, understanding angiogenesis and its mechanical process is crucial for the development of new treatment.

\section{Angiogenesis}

Angiogenesis refers to the formation of new capillary blood vessels from pre-existing ones. It is vital for normal development, growth of the organism, and in the physiological processes of wound healing, placenta formation, and in tumor growth (Folkman J, 2002; Mangi and Newland 2008).

The initiation of angiogenesis begins with the local release of proand anti-angiogenesis growth factors by endothelial cells (ECs). These released biomolecules diffuse into the surrounding tissue and bind to specific cell-surface receptors located on quiescent, macrovascular ECs in nearby post-capillary and small terminal venules. Thereafter, the ECs activate, proliferate and migrate from the parent vessel toward the source of the chemotactic angiogenesis stimulating factors (e.g. a diseased tissue).

\footnotetext{
Author Affiliation:

${ }^{a}$ Integrative Medicine Cluster, Advanced Medical and Dental Institute, Universiti Sains Malaysia, 13200 Kepala Batas, Penang, Malaysia.

${ }^{b}$ Faculty of Veterinary Medicine, Universiti Putra Malaysia, 43400 UPM Serdang, Selangor, Malaysia.

${ }^{c}$ Director, DigiCare Behavioral Research, Casa Grande, Arizona, USA.

${ }^{d}$ Department of Clinic and Internal Medicine, College of Veterinary Medicine, University of Sulaimani.

${ }^{\mathrm{e}}$ Department of Medical Laboratory Sciences, College of Health Sciences, Komar University of Science and Technology, Chaq Chaq Qularaese, Sulaimani City, Kurdistan Region, Northern Iraq.

Please cite this article:

Samad, Nozlena A; Abdul, Ahmad Bustamam; Abdullah, Rasedee; Rahman, Heshu; Khor KZ; Chartrand, Max Stanley. (2018). Angiogenic Switches Play a Critical Progression in Cancer. Angiotherapy, 1(2), pages 048-055. doi: 10.25163/angiotherapy.11000125480618
}

2207-8843/৫ 2018 ANGIOTHERAPY, a publication of Eman Research Ltd, Australia. This is an open access article under the CC BY-NC-ND license. (http://creativecommons.org/licenses/by-nc-nd/4.0/) 


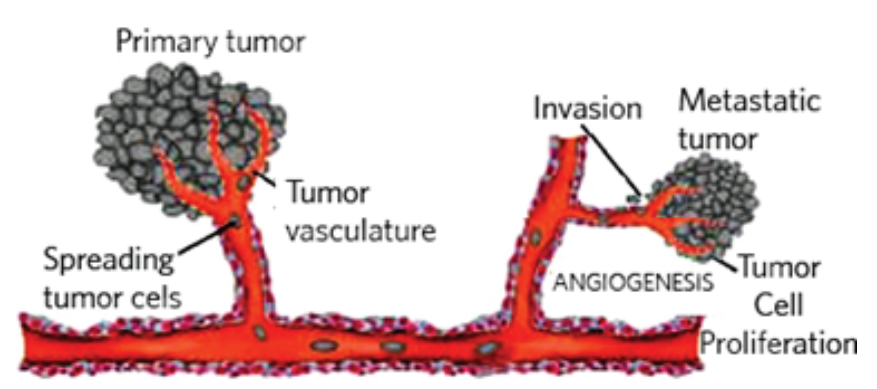

Figure 1| Tumour angiogenesis (Pandya et al., 2006).

tissue). The extracellular matrix (ECM) is remodeled once the ECs extend toward the diseased tissue and align to form a new capillary lumen. These will then form endothelial tubes and blood vessel loops allowing for blood circulation. As these capillaries form, the ECs stop proliferating, synthesize new basal membrane and establish inter-cell and EC-basal membrane junctions to stabilize the newly-formed vessels. Specialized structural support in the form of smooth muscle cells (SMCs) and pericytes that surround the endothelial tubes further stabilize the newly-formed blood capillaries (Duarte et al., 2004; Griffioen et al., 2000).

The term angiogenesis was first used to describe the formation of new blood vessels in the placenta 8 decades ago. It was then identified in wound healing and tumor growth. One study proposed that inhibition of angiogenesis may be a potential way of treating cancer as it can inhibit cancer progression (Folkman J, 2002).

The impact of tumor angiogenesis and the tumor microenvironment has been extensively studied in solid tumors (Figure 1). It was found, for instance, that the appropriate balance between anti-angiogenic and pro-angiogenic signals that arise from stromal and tumor cells in response to cell-ECM and/or direct cell-cell binding, as well as the response to paracrine and autocrine growth factor stimulation, is lost during tumorigenesis (Fan et al., 2012). The aforementioned angiogenic switch, which is a rapid increase of blood vessel formation in order to support cancer growth, is triggered by several factors (Hoeben et al., 2004; Kerbel, 2000). These are metabolic stress, genetic mutations, immune response, hypoxia (as well as oncogene-mediated tumor expression of antigenic proteins like platelet derived growth factor), fibroblast growth factor, vascular endothelial growth factor, endothelial growth factor, angiopoietin, and lysophosphatic acid (Weidner et al., 1993).

The main mechanism of cancer angiogenesis is endothelial sprouting that depends on vascular endothelial growth factor upregulation and the interaction between endothelial cells, pericytes, and stroma cells, as well as extracellular matrix (Figure 2) (Griffioen et al., 2000; Hoeben et al., 2004; Kerbel, 2000). Vascular endothelial growth factor and angiopoietin activate matrix degrading enzymes to loosen the matrix, in turn favours endothelial cells migration (Sang, 1998; McMahon, 2000).

Tumour cells, in this case, act as endothelial cells to form functional avascular blood conduits. Oxygen tension regulates vascular endothelial growth factor expression, mainly via the hypoxia-inducible factor or von Hippel-Lindautumor suppressor gene pathway (Kizaka-Kondoh et al., 2003; Hirota and Semenza 2006). Under normoxic conditions, prolyl hydroxylase domain proteins hydroxylateprolyl residues on the hypoxia-inducible factor and undergo proteasomal degradation. A decrease in oxygen tension leads to tumor growth. Consequently, the process of tumor angiogenesis is initiated and blood vessels supply oxygen and nutrients to the tumors in hypoxic or necrotic state. Under hypoxic conditions, prolyl hydroxylase domain proteins are inactive which leads to the accumulation of hypoxia-inducible factor (HIF). This hypoxia-inducible factor then translocates into the nucleus and binds to the hypoxia-response elements, in turn initiates transcription of the genes implicated in angiogenesis (Kizaka-Kondoh et al., 2003; Hirota and Semenza 2006; Gillies and Gatenby, 2007).

A key mediator of angiogenic response is hypoxia-inducible factor-1 (HIF-1), which is responsible for the transcriptional activation of a number of growth factors such as vascular endothelial growth factor (VEGF). Other genes that are induced by hypoxia-inducible factors are platelet derived growth factor, epidermal growth factor receptor, insulin-like growth factor 2, stromal cell-derived factor 1, glucose transporter 1, transforming growth factor- $\beta$, tumour growth factor $\alpha$, activin $B$ and carbonic anhydrase 9 (Kerbel, 2000; McMahon, 2000). The hypoxia-inducible factor is also regulated by oxygen-independent pathways through growth-factor receptors or signalling molecules. HIF-1a synthesis is triggered by signalling molecules, and growth factors, as well as loss of function mutations in molecules like p53, PTEN, and VHL. A recent study found that miR424, a unique microRNA in hypoxic endothelial cells, promotes hypoxia-inducible factor-1 stabilization, and angiogenesis (Ghosh et al., 2010). Besides being a key regulator of angiogenesis, hypoxia-inducible factor is required for cancer cell proliferation, survival, invasion, migration, metabolism, drug resistance, $\mathrm{pH}$ regulation, radiation resistance, and genetic stability, as well as immune evasion (Hirota and Semenza, 2006).

\section{Sprouting and Non-sprouting Angiogenesis}

Angiogenesis includes the sprouting, pruning branching, and differential growth of blood vessels to form the more mature-looking vascular patterns. The differential growth of vascular development requires differential recruitment of associated supporting cells. For instance, smooth muscle cells, fibroblasts, and pericytes (Heinke et al., 2012).

Sprouting angiogenesis refers to the formation of new blood vessels through the formation of a sprout in the wall of the existing 


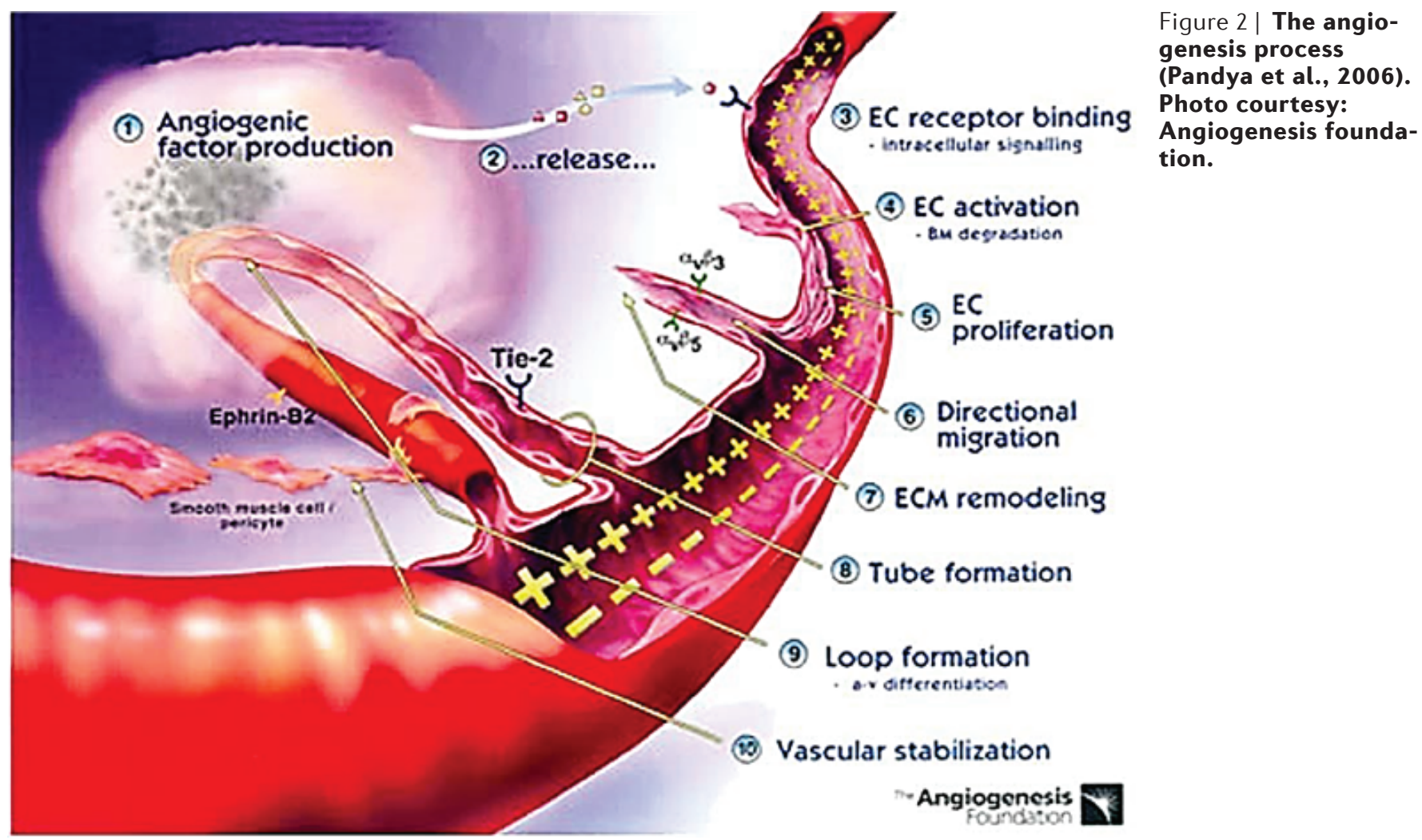

Figure 2 | The angiogenesis process

(Pandya et al., 2006).

(1) Angiogenic
factor production (2)...release...

- intracellular signalling Angiogenesis foundation.

seen in the vicinity of hypoxic tissue which secretes angiogenic factors. For example, a growing tumor that activates and attracts endothelial cells from the vessels. Sprouting angiogenesis enables the tumor to continue to grow and proliferate (Reinhart-King, 2012). The sprouts will not reach the tumor if the tumor cells are not able to divide and differentiate. A model showed that sprouting angiogenesis started with blood vessel at one side and a tumor on the opposite side (Reinhart-King, 2012). The tumor secretes a chemoattractant, which results in a gradient of chemoattractant that attracts cells towards the tumor. Haptotaxis is attracted by fibronectin, which the cells themselves secrete. The highest levels of fibronectin occur when the cell density is maximized. Thus, chemotaxis and haptotaxis work in opposite directions. Sprouting is restricted in the absence of proliferation (Green et al., 2009). According to Staton et al. 2004, new blood vessels outgrowths are formed by well characterized events in sprouting angiogenesis.

On the other hand, non-sprouting angiogenesis occurs via the enlargement and splitting of existing vessels with transcapillary posts or pillars of extracellular matrix (Burri et al., 2004). This takes place through in situ proliferation of endothelial cells in order to form a wide lumen (Figure 2). The wide lumen is then split by transcapillary pillars. Non-sprouting can occur concurrently with sprouting angiogenesis in the vascularization of tissues or organs like heart, lung and yolk sac during development (Yano et al., 2003). The mechanism of non-sprouting angiogenesis in respect to tumor metastasis is not yet known. However, vascular endothelial growth factor, which is also known as vascu- lar permeability factor, is said to play an important role in the development, and in physiological and pathological neovascularization (Folkman, 2002).

Both the sprouting and non-sprouting angiogenesis or intussusception form a functional extraembryonic vasculature (Figure 3). The sprouting angiogenesis accounts for a major contribution to the functional vascularization of certain organs like the brain (Kerbel 2000). The nonsprouting angiogenesis serves as a major mechanism for the formation of embryonic lung vasculature (Ribatti and Crivellato, 2012). The sprouting and non-sprouting angiogenesis are said to contribute to an increasing complexity of the growing vascular network. The network assembles and matures through the recruitment of smooth muscle cells and pericytes. Eventually, it allows a directional flow of blood. Morphogenic events leading to a mature vascular network involved a few additional steps like vessel assembly, maturation, acquisition of vessel identity as well as organotypic differentiation (Ribatti and Crivellato, 2012).

\section{Angiogenesis Mediators}

Angiogenic growth factors and cytokines are the mediators of angiogenesis (Owen et al., 2013). Among the most commonly described cytokines and angiogenic growth factors that act as mediators for angiogenesis include fibroblast growth factor, vascular endothelial growth factor, tumor necrosis factor-alpha, angiopoietins, and transforming growth factor-beta (Yoshida et al., 1997). Sources of these growth factors are fibroblasts, endothelial cells, platelets, smooth muscle cells, cancer cells, and inflammatory cells. Certain growth factors like basic fibroblast growth 


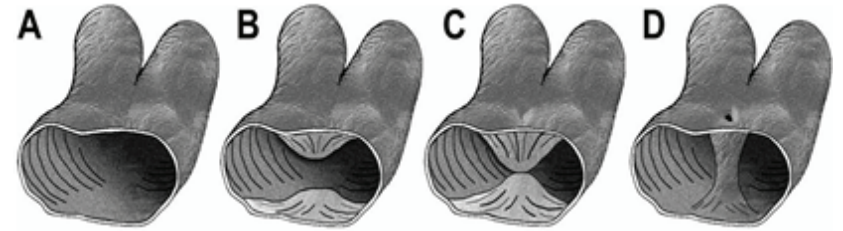

Figure 3 | Non-sprouting angiogenesis (Kurz et al. 1996)

extracellular matrix. They serve as the reservoirs for sustained cellular-demanded growth factor release (Gutiérrez and Brandan, 2010).

Vascular endothelial growth factor (VEGF) is one of the most well-studied mediators involved in the endothelial cells migration, sprouting, mitogenesis, and tube formation (Verheuland Pinedo, 2000). VEGF promotes integrin expression, plasminogen activator, interstitial collagenase expression, plasminogen activator receptor expression, as well as increases in both vascular fenestration and permeability (Neufeld et al., 1999). The upregulated VEGF and VEGF-receptor mRNA were detected in the tips of invasive angiogenic sprouts. In addition, antibody blockade of VEGF significantly decreases microvessel outgrowth (Dougher et al., 1997) A study has shown that use of heparin and heparansulfateprotegolycan binding contributes to VEGF and VEGFreceptor binding. This stabilizes the active conformation of VEGF, prevents its degradation and has greatly increased the angiogenic response of endothelial cells to VEGF in type 1 collagen matrix (Stephen et al., 2004).

Fibroblast growth factor is also a mediator of angiogenesis. It is stored in the vascular basement membrane in order to serve as a reservoir supply, and is upregulated during angiogenesis (Ucuzian et al., 2010). Both FGF-1 and FGF-2 bind to the receptor tyrosine kinases, FGFR-1 and FGFR-2. The binding of FGF to FGFR-1 increase endothelial cell migration and promotes capillary morphogenesis when cultured on collagen gels Ucuzian et al., 2010; Böhm et al., 2010).

Like other mediators of angiogenesis, angiopoietins represent a group of receptor tyrosine kinases that function primarily during angiogenesis and vascular remodeling. They are a family of extracellular ligands, which bind to the endothelial specific tie receptors (Brindle et al., 2006). Although angiopoietin-1 and 2 bind to the same receptor, Tie-2, they elicit different responses (Ahmad et al., 2010). Angiopoietin-1 serves as an agonist that causes rapid receptor transphosphorylation that leads to subsequent downstream activation of protein kinase B pathway to inhibit Angiopoietin-2 expression and to promote endothelial cell survival. On the other hand, angiopoietin-2 induces an autocrine response, which in the presence of VEGF, serves as a competitive antagonist of Angiopoietin-1 to prevent Tie-2 receptor phosphorylation and signaling(Yuan et al., 2009).

Transforming Growth Factor- $\beta$ is a mediator of angiogenesis as well. It promotes extracellular matrix deposition and integrin receptor upregulation (Weston et al., 2003). It is one of the most important cytokines for the formation of granulation tissue as well as modulating endothelial cell proliferation, migration, and capillary tube formation (Tonnesen et al., 2000). It was found that TGF- $\beta$ can inhibit angiogenesis in a receptor specific manner directly. It has the ability to recruit inflammatory cells that act as a source of pro-angiogenic signals. In addition, TGF- $\beta$ is able to modulate other angiogenesis pathways, which account for its pro-angiogenic effects (Wang et al., 2013).

TNF- $\alpha$, being a mediator of angiogenesis, is secreted by activated macrophages during immune response and inflammation (Chang and Ding, 2014). It is associated with endothelial cells, mast cells, myocytes, fibroblasts, neuronal tissue, and adipose tissue. Its functions include stimulation of interleukin-1 and granulocyte-macrophage-colony stimulating factor. Furthermore, it has been suggested that it acts on endothelial cells directly and induce cell differentiation as well as indirectly and stimulate production of angiogenic factors (Stenmark et al., 2006).

\section{The Role of Angiogenesis in Solid Tumours}

Solid tumors are not able to grow over a few millimeteres without angiogenesis (Kerbel, 2000). This statement is further supported by Vaupel et al., 2004, which suggested that oxygen and nutrition supplies are necessary for solid tumours, when being more than several millimetres in diameter. Oxygen and nutrient supplies come from the newly generated blood vessels. Without effective angiogenesis, the large tumor would soon outstrip the physiologic blood supply, develop a necrotic core, and die. Therefore, solid tumors must be able to allow for and encourage angiogenesis as the tumor mass expands. Thus, the role and involvement of angiogenesis in solid tumours is imperative (Vaupel et al., 2004).

Folkman and his co-workers started to work on angiogenesis four decades ago, and postulated that solid tumors are angiogenesis-dependent. This initiated a great deal of research relative to angiogenesis and tumor biology. Consequently, over the past 30 years, around 17,000 papers have been published on the angiogenic process and its role in solid tumors (Nicosia et al., 1998).

The role of angiogenesis in solid tumors has been proven when it was demonstrated that the microvascular density of bone marrow increased significantly in multiple myeloma in comparison to monoclonal gammopathy (Zou et al., 2010). The microvascular density of bone marrow also increased in active multiple myeloma compared to non-active myeloma (Vacca et al., 2001).

In multiple myeloma mass, angiogenesis favors the expansion of the tumor by promoting plasma cell proliferation (Ria et al., 2003). Myeloma plasma cells promotes angiogenesis directly through the secretion of angiogenic cytokines (Giuliani et al., 2011).

Likewise, in a study which comprised 51 children with acute 


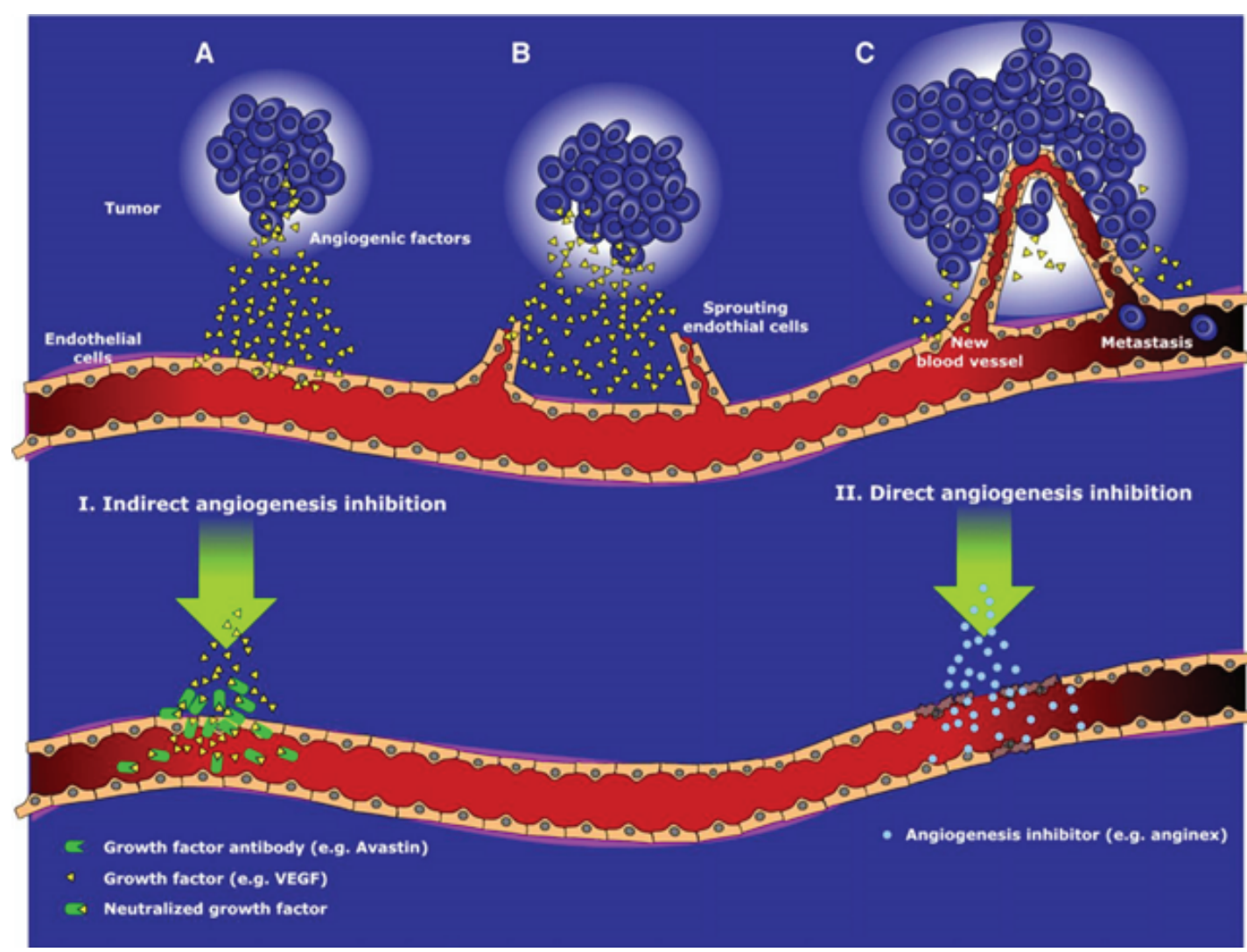

Figure 4 | The angiogenesis pathways and the examples of its inhibition (Griffioen, 2007).

lymphocytic leukaemia, the microvascular density in bone marrow was found to increase six-to-seven fold in comparison to control group bone marrow of children evaluated for primary tumors (Alexandrakis et al., 2004).

Urinary levels of fibroblast growth factor-2, (FGF-2) were higher in children with acute lymphocytic leukaemia before induction therapy, which were normalized after therapy. FGF-2 is a mediator of angiogenesis. This provided evidence that angiogenesis is essential for tumor growth. These findings were further supported by the findings by List, 2001, who found increased bone marrow microvascular density in acute lymphocytic leukaemia. The investigation also identified increased plasma levels of FGF-2 in acute lymphocytic leukaemia patient, but VEGF did not increase (List, 2001).

\section{Anti-angiogenesis as Therapeutic Agent in Cancer}

Blood vessels of tumors differ from normal resting blood vessels. The difference of special tumor blood vessels makes them reliable targets for tumor-directed treatment (Dudley, 2012). Moreover, anti-angiogenic therapeutic agents may act by neutralizing the angiogenic proteins, inhibiting synthesis of angiogenic proteins by cancer cells, directly inducing endothelial cell apoptosis or inhibiting endothelial receptors for angiogenic proteins (Figure 4). The anti-angiogenic inhibitors include small molecules and therapeutic antibodies that are capable of targeting angiogenic growth factors like bFGF and VEGF or angiogenic growth factor receptors like PDGFR and VEGFR. (Daly, 2003). The anti-angiogenic efficacy of the therapeutic agents is best observed when used in low dosages on a frequent or continuous schedule. Metronomic chemotherapy is defined by the frequent administration of chemotherapeutic agents at doses below the maximum tolerated doses with no prolonged drug-free breaks (Maiti, 2014). In reference to this, it was found that the main targets of metronomic chemotherapy were the endothelial cells involved in the expanding vasculature of a tumor. Besides reducing acute toxicity, the efficacy of metronomic chemotherapy seems to increase when used in combination with certain antiangiogenic therapeutic agents (Ma and Waxman, 2008). Several studies showed that endothelial cells of newly forming blood vessel capillaries are highly sensitive to low doses of chemotherapeutic drugs.

These studies involved microtubule inhibitors like paclitaxel, docetaxel and vinblastine (Kerbel and Kamen, 2004).

The use of anti-angiogenic agents to normalize tumor vasculature is an emerging concept to improve the efficacy of radiotherapy and cytotoxic chemotherapy (Loges et al., 2010). Likewise, it has been found that anti-angiogenic agents can normalize tumor vasculature and hence improve delivery of cytotoxic agents administered during the normalization window (Goe et al., 2011).

Furthermore, there are fewer side effects and less drug resistance towards antiangiogenic agents in comparison to chemotherapy agents with the above-described approach. The combination of anti-angiogenic agents with conventional chemotherapy agents can therefore possibly enhance quality of life for cancer patients. In 2004, FDA approved bevacizumab or Avastin for the treatment of metastatic colorectal cancer in combination with 5-fluorouracil 
(Gaulin et al., 2009). Bevacizumab is a monoclonal antibody, which acts on vascular endothelial growth factor. It was later found to assist in halting tumor growth and metastasis by blocking tumor angiogenesis (Duignan et al., 2011).

Another effective anti-angiogenic drug that has been approved is aflibercept. Aflibercept is formed from the combination of two VEGFR1 and three VEGFR2 within the Fc region of IgG1 (Moroney et al., 2009). This fusion protein allows aflibercept to block the activity of VEGF at very low lwvels. In addition, aflibercept has a long half-life, which allows long-term tumor angiogenesis blockage (Semeraro et al., 2013). Aflibercept caused significant tumor regression in pre-clinical studies and decreased tumor vascularity. In addition, Sunitinib acts an an ATP-competitive inhibitor of PDGFRs, FLT3, VEGFR1, VEGFR2, VEGFR3, RET and c-Kit. These activities lead to the inhibition of tumor growth, progression, angiogenesis, and metastasis (Cai et al., 2011).

\section{Anti-angiogenesis from Plant Origin}

Scientists have been looking for angiogenesis inhibitors and promoters from natural products for the past fifteen years. This may be due to the potential of natural product to act through multiple cell-signaling pathways and decrease the development of resistance by cancer cells. Therefore a number of angiogenesis inhibitors derived from plant were screened in order to study their potential as anti-angiogenesis inhibitors.

A study to the anti-angiogenic properties of pterogynidine alkaloid, derived from Alchorneaglandulosa, was carried out using human umbilical vein endothelial cells. It was found that there was an increase in apoptosis, significant decrease in tumor proliferation, as well as invasion capacity when the pterogynidine alkaloid was used. In addition, pterogynidine alkaloid also caused a drastic reduction in the number of capillary-like structures formation in the tumor. This showed that pterogynidine can be used to treat pathological situations like tumor development (Sureram et al.,2012).

Likewise, Raga et al., 2011 studied the anti-angiogenic properties of the leaf extracts of Ardisiapyramidalis. It was found that the methanol extract of the leaf was antiangiogenic as it showed statistically significant lower blood vessels count in comparison to the negative control and untreated eggs. It was concluded that Ardisiapyramidalis can be used as a chemotherapeutic agent for cancer therapy (Raga et al., 2011)

Tylophorine has also been identified as a potential anti-angiogenic agent for cancer therapy. Tylophorine is a phenanthraindolizidine alkaloid, which was isolated from Tylophoraindica. It was found that Tylophorine exerts antitumour and antiangiogenic properties by targeting vascular endothelial growth factor receptor 2, which is a mediator of angiogenesis. It inhibits a series of VEGF-induced angiogenesis processes, including migration and proliferation, as well as tube formation of endothelial cells. Tylophorine also inhibits VEGF-stimulated inflammatory responses that include TNF-alpha, IFN-gamma, IL6, IL-8, MMP-2 and NO secretion. Hence, the study concluded that Tylophorine is a viable drug for cancer therapy due to its anti-angiogenesis effects through VEGFR2 signalingpathway (Saraswati et al., 2013).

The essential oil isolated from Tridaxprocumbens L. has shown promising activity on lung metastasis by inhibiting tumor nodule formation. The formation of tumor-directed new blood vessels was also inhibited with the use of this essential oil. The investigation demonstrated further that this essential oil significantly induced apoptosis and suppressed angiogenesis in tumor cells. Hence, Tridaxprocumbens L can be useful to help prevent lung metastasis in lung cancer cell (B16F-10), due to its antiangiogenesis effect and its ability to induce apoptosis (Manjamalai and Grace, 2013).

Another antiangiogenic agent, derived from plant origin, is combretastatins. Combretastatins were derived from Combretumcaffrum, a South African bush willow (63). They belong to the family of stilbenes, which possess anti-angiogenic properties that cause vascular shutdown in cancer, leading to tumor necrosis. Two water-soluble analogues, combretastatin A-phosephase and combretastatin A-4 phosphate, are placed under clinical trials against cancer therapy (Kanthou and Tozer, 2009). To date, there are 12 clinical trials that involve CA4P against various cancers, mostly in combination with other agents like paclitaxel and carboplatin. Combretastatin A1P showed excellent antiangiogenic activity in preclinical studies. Its safety and tolerability in patients with solid tumors are still currently being investigated as we go to press (Risinger et al., 2009).

Plant-derived polyphenols have been studied for several years for their anti-angiogenic properties. Red wine polyphenols were found to have a unique dual effect that provides important therapeutic properties for the treatment of cancer (Baron-Menguy et al., 2007). In high doses, red wine polyphenols exhibit anti-angiogenic effects through the mediation of PI3k-Akt-eNOS pathways and potential MMP modulation. On the other hand, Resveratrol, a plant derivative, is able to inhibit tumor-induced neovascularisation as a result of blockage of both bFGFreceptor and VEGF mediated responses involving MAPK phosphorylation (Gupta et al., 2010). The application of red wine and green tea polyphenols into the chick embryo choroallantoic membrane were shown to significantly inhibit angiogenesis. Green tea polyphenols were also found to diminish tumor growth, tumor cell proliferation, and microvessel density. In addition, infusions of green tea polyphenols were able to reduce angiogenesis and metastasis markers like VEGF (Khan and Mukhtar, 2010).

Thus, results from plant derived anti-angiogenesis agent suggest that unlike conventional chemotherapeutic agents that are gener- 
rally employed at high doses for relatively short time periods,these angiogenic inhibitors may be best employed using less cytotoxicdoses over months to years as a potential means to prevent dormant micrometastases from entering a rapid growth phase. The additional clinical testing of newly identified angiogenic inhibitors using a variety of delivery strategies is eagerly awaited.

\section{Conclusion}

Angiogenesis plays a crucial to thwart tumor growth in various cancers. Blocking the proliferation of angiogenesis, then, could be a viable approach to halting both tumor growth and metastasis.

\section{Acknowledgment \\ The author would like to acknowledge the USM:RLKA Scheme and USM Short Term Grant 304/CIPPT/6313315.}

\section{Author Contribution}

Samad, Nozlena A; Abdul, Ahmad Bustamam; Abdullah, Rasedee; Rahman, Heshu; Khor KZ; Chartrand, Max Stanley performed all aspects of the project.

\section{Competing financial interests}

The author(s) declare no competing financial interests.

\section{References}

Ahmad S, Cudmore MJ, Wang K, Hewett P, Potluri R, Fujisawa T, et al. (2010). Angiopoietin-1 induces migration of monocytes in a tie-2 and integrin-independent manner. Hypertension, 56(3), 477-83. https://doi.org/10.1161/HYPERTENSIONAHA.110.155556. PMid:20696992

Alexandrakis MG, Passam FH, Dambaki C, Pappa CA, Stathopoulos EN. (2004). The relation between bone marrow angiogenesis and the proliferation index Ki-67 in multiple myeloma. J ClinPathol. 2004 Aug;57(8):856-60. https://doi.org/10.1136/jcp.2003.013110. PMid:15280408 PMCid:PMC1770397

Baron-Menguy C, Bocquet A, Guihot A-L, Chappard D, Amiot M-J, Andriantsitohaina R, et al. (2007). Effects of red wine polyphenols on postischemic neovascularization model in rats: low doses are proangiogenic, high doses antiangiogenic. FASEB J., (13), 3511-21. https://doi.org/10.1096/fj.06-7782com. PMid:17595348 Böhm F, Speicher T, Hellerbrand C, Dickson C, Partanen JM, Ornitz DM, et al. (2010). FGF receptors 1 and 2 control chemically induced injury and compound detoxification in regenerating livers of mice. Gastroenterology, 139(4), 1385-96. https://doi.org/10.1053/j.gastro.2010.06.069. PMid:20603121 PMCid:PMC2949525 Brindle NPJ, Saharinen P, Alitalo K. (2006). Signaling and functions of angiopoietin-1 in vascular protection. Circ Res., 98(8), 1014-23. https://doi.org/10.1161/01.RES.0000218275.54089.12. PMid:16645151 PMCid:P MC2270395

Burri PH, Hlushchuk R, Djonov V. (2004). Intussusceptive angiogenesis: its emergence, its characteristics, and its significance. DevDyn, 231(3), 474-88. https://doi.org/10.1002/dvdy.20184

Cai J, Han S, Qing R, Liao D, Law B, Boulton ME. (2011). In pursuit of new anti-angiogenic therapies for cancer treatment. Front Biosci. 16, 803-14. https://doi.org/10.2741/3721

Chang SC, Ding JL. (2014). Ubiquitination by SAG regulates macrophage survival/death and immune response during infection. Cell Death Differ. Macmillan Publishers Limited. Daly ME. (2003). Hemostatic Regulators of Tumor Angiogenesis: A Source of Antiangiogenic Agents for Cancer Treatment? Cancer Spectrum Knowl Environ., 95(22), 1660-73. https://doi.org/10.1093/jnci/djg101

Duarte A, Hirashima M, Benedito R, Trindade A, Diniz P, Bekman E, et al. (2004). Dosagesensitive requirement for mouse DII4 in artery development. Genes Dev., 18(20), 2474-8. https://doi.org/10.1101/gad.1239004. PMid:15466159 PMCid:PMC529534 Dudley AC. (2012). Tumor endothelial cells. Cold Spring HarbPerspect Med., 2(3). https://doi.org/10.1101/cshperspect.a006536. PMid:22393533 PMCid:PMC3282494 Duignan IJ, Corcoran E, Pennello A, Plym MJ, Amatulli M, Claros N, et al. (2011). Pleiotropic Stromal Effects of Vascular Endothelial Growth Factor Receptor 2 Antibody Therapy in Renal Cell Carcinoma Models. Neoplasia, 13(1), 49-59. https://doi.org/10.1593/neo.101162. PMid:21245940 PMCid:PMC3022428

Fan F, Schimming A, Jaeger D, Podar K. (2012). Targeting the tumor microenvironment: focus on angiogenesis. J Oncol., 281261. https://doi.org/10.1155/2012/281261 PMid:21876693 PMCid:PMC3163131

Folkman J. (2002). Role of angiogenesis in tumor growth and metastasis. SeminOncol., 29(6), 15-8. https://doi.org/10.1016/S0093-7754(02)70065-1

Gaulin J, Kotb R, Turcotte E, Berard G, Sawan B, Schmutz G, et al. (2009). Efficacy of thirdline therapy using bevacizumab in a patient with metastatic colorectal cancer. CurrOncol., 16(5), 84-6. PMid:19862366 PMCid:PMC2768516

Ghosh G, Subramanian I V, Adhikari N, Zhang X, Joshi HP, Basi D, et al. (2010). Hypoxiainduced microRNA-424 expression in human endothelial cells regulates HIF-a isoforms and promotes angiogenesis. J Clin Invest., 120(11), 4141-54.

https://doi.org/10.1172/JCI42980. PMid:20972335 PMCid:PMC2964978

Gillies RJ, Gatenby RA. (2007). Hypoxia and adaptive landscapes in the evolution of carcinogenesis. Cancer Metastasis Rev., 26(2), 311-7. https://doi.org/10.1007/s10555-007-9065-z. PMid:17404691

Giuliani N, Storti P, Bolzoni M, Palma BD, Bonomini S. (2011). Angiogenesis and multiple $\begin{array}{llll}\text { myeloma. } & \text { Cancer } & \text { 3(3), } & \text { 325-37oenviron., }\end{array}$ https://doi.org/10.1007/s12307-011-0072-9. PMid:21735169 PMCid:PMC3234322 Goel S, Duda DG, Xu L, Munn LL, Boucher Y, Fukumura D, et al. (2011). Normalization of the vasculature for treatment of cancer and other diseases. Physiol Rev., 91(3), 1071-121. https://doi.org/10.1152/physrev.00038.2010. PMid:21742796 PMCid:PMC3258432

Green CE, Liu T, Montel V, Hsiao G, Lester RD, Subramaniam S, et al. (2009). Chemoattractantsignaling between tumor cells and macrophages regulates cancer cell migration, metastasis and neovascularization. PLoS One, 4(8), e6713. https://doi.org/10.1371/journal.pone.0006713. PMid:19696929 PMCid:PMC2725301

Griffioen AW, Molema G. (2000). Angiogenesis: Potentials for Pharmacologic Intervention in the Treatment of Cancer, Cardiovascular Diseases, and Chronic Inflammation. Pharmacol Rev., 52(2), 237-68. PMid:10835101

Gupta SC, Kim JH, Prasad S, Aggarwal BB. (2010). Regulation of survival, proliferation, invasion, angiogenesis, and metastasis of tumor cells through modulation of inflammatory pathways by nutraceuticals. Cancer Metastasis Rev, 29(3), 405-34. https://doi.org/10.1007/s10555-010-9235-2. PMid:20737283 PMCid:PMC2996866 Gutiérrez J, Brandan E. (2010). A novel mechanism of sequestering fibroblast growth factor 2 by glypican in lipid rafts, allowing skeletal muscle differentiation. Mol Cell Biol., 30(7), 1634-49 
Heinke J, Patterson C, Moser M. (2012). Life is a pattern: vascular assembly within the embryo. Front Biosci, 4, 2269-88. https://doi.org/10.2741/e541

Hirota K, Semenza GL. (2006). Regulation of angiogenesis by hypoxia-inducible factor

1. Crit Rev OncolHematol., 59(1), 15-26. https://doi.org/10.1016/j.critrevonc.2005.12.003. PMid:16716598

Hoeben A, Landuyt B, Highley MS, Wildiers H, Van Oosterom AT, De Bruijn EA. (2004) Vascular endothelial growth factor and angiogenesis. Pharmacol Rev., 56(4), 549-80. https://doi.org/10.1124/pr.56.4.3. PMid:15602010

Kanthou C, Tozer GM. (2009). Microtubule depolymerizing vascular disrupting agents: novel therapeutic agents for oncology and other pathologies. Int J ExpPathol., 90(3), 284-94. https://doi.org/10.1111/j.1365-2613.2009.00651.x

Kerbel RS, Kamen BA. (2004). The anti-angiogenic basis of metronomic chemotherapy. Nat Rev Cancer, 4(6), 423-36. https://doi.org/10.1038/nrc1369. PMid:15170445

Kerbel RS. (2000). Tumor angiogenesis: past, present and the near future. Carcinogenesis. 21(3), 505-15. https://doi.org/10.1093/carcin/21.3.505

Kerbel RS. (2000). Tumor angiogenesis: past, present and the near future. Carcinogenesis, 21(3), 505-15. https://doi.org/10.1093/carcin/21.3.505

Khan N, Mukhtar H. (2010). Cancer and metastasis: prevention and treatment by green tea. Cancer Metastasis Rev., 29(3), 435-45. https://doi.org/10.1007/s10555-010-9236-1. PMid:20714789 PMCid:PMC3142888 Kizaka-Kondoh S, Inoue M, Harada H, Hiraoka M. (2003). Tumor hypoxia: A target for selective cancer therapy. Cancer Sci., 94(12), 1021-8. https://doi.org/10.1111/j.1349-7006.2003.tb01395.x. PMid:14662015

List AF. (2001). Vascular Endothelial Growth Factor Signaling Pathway as an Emerging Target in Hematologic Malignancies. Oncologist, 6(90005), 24-31. https://doi.org/10.1634/theoncologist.6-suppl_5-24

Loges S, Schmidt T, Carmeliet P. (2010). Mechanisms of resistance to anti-angiogenic therapy and development of third-generation anti-angiogenic drug candidates. Genes Cancer, 1(1), 12-25. https://doi.org/10.1177/1947601909356574. PMid:21779425

\section{PMCid:PMC3092176}

Ma J, Waxman DJ. Combination of antiangiogenesis with chemotherapy for more effective cancer treatment. Mol Cancer Ther. 2008 Dec;7(12):3670-84.

https://doi.org/10.1158/1535-7163.MCT-08-0715. PMid:19074844 PMCid:PMC2637411

Maiti R. (2014). Metronomic chemotherapy. J Pharmacol Pharmacother., 5(3), 186. https://doi.org/10.4103/0976-500X.136098. PMid:25210398 PMCid:PMC4156829

Mangi MH, Newland AC. (2008). Angiogenesis and Angiogenic Mediators In Haematology Malignancies. $\mathrm{Br}$ J Haematol., 111(1), 43-51. https://doi.org/10.1111/j.1365-2141.2000.02104.x

Manjamalai A, Grace, B. (2013). Chemotherapeutic Effect of Essential Oil of Wedeliachinensis (Osbeck) on Inducing Apoptosis, Suppressing Angiogenesis and Lung Metastasis in C57BL/6 Mice Model. J Cancer SciTher., 5, 271-281. https://doi.org/10.4172/1948-5956.1000216

McMahon G. (2000). VEGF Receptor Signaling in Tumor Angiogenesis. Oncologist, 5(90001), 3-10. https://doi.org/10.1634/theoncologist.5-suppl_1-3. PMid:10804084 Moroney JW, Sood AK, Coleman RL. (2009). Aflibercept in epithelial ovarian carcinoma. Future Oncol., 5(5), 591-600. https://doi.org/10.2217/fon.09.35. PMid:19519199 PMCid:PMC2744352

Nicosia RF. (1998). What is the role of vascular endothelial growth factor-related molecules in tumor angiogenesis? Am J Pathol., 153 (1), 11-6. https://doi.org/10.1016/S0002-9440(10)65539-3

Nielsen T, Wittenborn T, Horsman MR. (2012). Dynamic Contrast-Enhanced Magnetic Resonance Imaging (DCE-MRI) in Preclinical Studies of Antivascular Treatments. Pharmaceutics, 4(4), 563-89. https://doi.org/10.3390/pharmaceutics4040563

\section{PMid:24300371 PMCid:PMC3834929}

Owen JL, Mohamadzadeh M. (2013). Macrophages and chemokines as mediators of angiogenesis. Front Physiol. Frontiers, 4, 159. https://doi.org/10.3389/fphys. 2013.00159

Raga DD, Alimboyoguen AB, Shen C-C, Herrera AA, Ragasa CY. (2011). Triterpenoids and an Anti-Angiogenic Sterol from Ardisiapyramidalis (Cav.) Pers. The Philippine Agricultural Scientist.

Reinhart-King C. (2012). Mechanical and Chemical Signaling in Angiogenesis. Springer Science \& Business Media.

Ria R, Roccaro AM, Merchionne F, Vacca A, Dammacco F, Ribatti D. (2003). Vascular endothelial growth factor and its receptors in multiple myeloma. Leukemia, 17(10), 1961-6. https://doi.org/10.1038/sj.leu.2403076. PMid:14513045

Ribatti D, Crivellato E. (2012). "Sprouting angiogenesis", a reappraisal. Dev Biol., 372(2), 157-65. https://doi.org/10.1016/j.ydbio.2012.09.018. PMid:23031691

Risinger AL, Giles FJ, Mooberry SL. (2009). Microtubule dynamics as a target in oncology. Cancer Treat Rev., 35(3), 255-61. https://doi.org/10.1016/j.ctrv.2008.11.001. PMid:19117686 PMCid:PMC2778221

Sang QX. (1998). Complex role of matrix metalloproteinases in angiogenesis. Cell Res. Shanghai Institutes for Biological Sciences, Chinese Academy of Sciences, 8(3), 171-7. Saraswati S, Kanaujia PK, Kumar S, Kumar R, Alhaider AA. (2013). Tylophorine, a phenanthraindolizidine alkaloid isolated from Tylophoraindica exerts antiangiogenic and antitumor activity by targeting vascular endothelial growth factor receptor 2 mediated angiogenesis. Mol Cancer., 12(1), 82. https://doi.org/10.1186/1476-4598-12-82 PMid:23895055 PMCid:PMC3733984

Semeraro F, Morescalchi F, Duse S, Parmeggiani F, Gambicorti E, Costagliola C. (2013). Aflibercept in wet AMD: specific role and optimal use. Drug Des DevelTher., 7, 711-22. https://doi.org/10.2147/DDDT.S40215

Staton CA, Stribbling SM, Tazzyman S, Hughes R, Brown NJ, Lewis CE. (2004). Current methods for assaying angiogenesis in vitro and in vivo. Int J ExpPathol., 85(5), 233-48. https://doi.org/10.1111/j.0959-9673.2004.00396.x

Submit your next manuscript to Angiotherpay published by EMAN Research.

- Convenient online submission

- Thorough peer review

- No space constraints or color figure charges

- Immediate publication on acceptance

- Inclusion in Australian National Libraray and Google Scholar

- Both Open (80-100\% subsidized APC by ER) \& non-open access option

Submit your manuscript at angiotherapy.emanresearch.org 